\title{
The effect of reminder systems on patients' adherence to treatment
}

\author{
This article was published in the following Dove Press journal: \\ Patient Preference and Adherence \\ 20 February 2012 \\ Number of times this article has been viewed
}

\author{
Sarah D Fenerty' \\ Cameron West' \\ Scott A Davis' \\ Sebastian G Kaplan ${ }^{3}$ \\ Steven R Feldman 1,2,4 \\ 'Center for Dermatology Research, \\ Department of Dermatology, \\ ${ }^{2}$ Department of Pathology, \\ ${ }^{3}$ Department of Psychiatry and \\ Behavioral Medicine, ${ }^{4}$ Department \\ of Public Health Sciences, Wake \\ Forest University School of \\ Medicine, Winston-Salem, North \\ Carolina, USA
}

Background: Patient adherence is an important component of the treatment of chronic disease. An understanding of patient adherence and its modulating factors is necessary to correctly interpret treatment efficacy and barriers to therapeutic success.

Purpose: This meta-analysis aims to systematically review published randomized controlled trials of reminder interventions to assist patient adherence to prescribed medications.

Methods: A Medline search was performed for randomized controlled trials published between 1968 and June 2011, which studied the effect of reminder-based interventions on adherence to self-administered daily medications.

Results: Eleven published randomized controlled trials were found between 1999 and 2009 which measured adherence to a daily medication in a group receiving reminder interventions compared to controls receiving no reminders. Medication adherence was measured as the number of doses taken compared to the number prescribed within a set period of time. Meta-analysis showed a statistically significant increase in adherence in groups receiving a reminder intervention compared to controls ( $66.61 \%$ versus $54.71 \%$, $95 \%$ CI for mean: $0.8 \%$ to $22.4 \%$ ). Self-reported and electronically monitored adherence rates did not significantly differ $(68.04 \%$ versus $63.67 \%, P=1.0$ ). Eight of eleven studies showed a statistically significant increase in adherence for at least one of the reminder group arms compared to the control groups receiving no reminder intervention.

Limitations: The data are limited by imperfect measures of adherence due to variability in data collection methods. It is also likely that concomitant educational efforts in the study populations, such as instructions regarding proper administration and importance of correct dosing schedules, contributed to improved patient adherence, both in reminder and control arms. The search strategy could have missed relevant studies which were categorized by disease rather than adherence.

Conclusions: Reminder-based interventions may improve adherence to daily medications. However, the interventions used in these studies, which included reminder phone calls, text messages, pagers, interactive voice response systems, videotelephone calls, and programmed electronic audiovisual reminder devices, are impractical for widespread implementation, and their efficacy may be optimized when combined with alternative adherence-modifying strategies. More practical reminder-based interventions should be assessed to determine their value in improving patient adherence and treatment outcomes.

Keywords: patient adherence, medication reminders, treatment compliance

\section{Introduction}

Patient adherence has gained increased recognition for its essential role in treatment efficacy. Failure to follow the recommendations of healthcare providers limits the 
achievement of therapeutic goals. ${ }^{1}$ Since the first patient adherence studies in 1968, ${ }^{2,3}$ numerous attempts have been made to understand, predict, and ultimately enhance patient adherence to medical recommendations. ${ }^{4,5}$ Inadequate adherence contributes to morbidity and mortality and raises healthcare expenditure, ${ }^{6-9}$ although the nature of this relationship may be more complex than originally thought. ${ }^{10}$ This is a significant and widespread issue in a population that is increasingly reliant on complex pharmacologic therapy. Up to $30 \%-50 \%$ of patients are expected to demonstrate poor adherence to medication use, regardless of disease process, prognosis, or background. ${ }^{7,9,11-13}$ With a significant number of patients relying upon pharmacologic treatment of chronic health conditions, failure to adhere to optimal treatment regimens may adversely affect both patient outcomes and healthcare costs.

Adherence is a relatively recent term that has replaced the notion of compliance when describing patient medicationtaking behaviors. ${ }^{14,15}$ Compliance is defined as the degree to which actual patient drug administration corresponds to the prescribed treatment regimen; ${ }^{16}$ integral to this definition is the assumption that medical advice confers benefit to the patient, or that rational behavior dictates necessitate obedience to medical advice. ${ }^{17} \mathrm{~A}$ broader definition also encompasses the extent to which behaviors such as lifestyle modifications or diets concur with medical advice. ${ }^{18}$ Compliance may also be measured by outcome-oriented definitions, in which the number of prescribed doses taken may determine whether a therapeutic result is achieved. ${ }^{19}$ Yet the term is associated with complaisance; the compliant patient submits to their doctor's directives, while the noncompliant patient appears disobedient. The passive connotations that the term compliance assigns to the patients' role in the healthcare process has led to a decline in its use.

Adherence has gained popularity as an alternative descriptor because it implies a more reciprocal dynamic in the doctor-patient relationship and recognizes salient influences on medication-taking behavior. ${ }^{14,15,20}$ However, multiple studies assessed in this analysis use the term compliance to describe medication-taking behaviors amongst study participants. Because of its prevalence in the literature, compliance was incorporated into this analysis. Yet the distinction between compliance and adherence is important; patient motivations must be taken into account to fully explain patterns of medication usage. The determinants of adherence are complex. Studies of adherence modifiers, such as those analyzing reminder systems, focus on the multifaceted motivations behind medication-taking behavior. Barriers to adherence vary widely, and include concerns about efficacy, fear of side effects, inconvenience, a poor doctor-patient relationship, lack of social support, patient motivation, or incorrect education regarding proper use..$^{21,22}$ Research regarding the theoretical groundwork of adherence, impediments, facilitators, and interventions serve to highlight its complexity and the practical difficulties of improving adherence in a patient population. ${ }^{23-28}$ Over 200 variables influencing compliance, such as socioeconomic factors and disease pathology, have been studied since 1975, yet none have demonstrated a consistent link with adherence rates..$^{8,9,29-32}$ Furthermore, studies of adherence vary significantly in methodology, patient population, disease processes, treatment regimens, and definition of adherence. The variation in study context and measurement is likely to account for significant disparities of observed adherence outcomes. Measures of adherence vary between studies; some use outcome oriented measures, others use a predetermined percent of doses taken to categorize patients as adherent or non-adherent, while some measure adherence more fluidly, reporting the overall percentage of total doses taken.

Patient adherence has substantial implications in preventative medicine and the treatment of chronic disease. It is a key component of successful medical management; an understanding of patient adherence and its modulating factors is crucial to interpreting treatment efficacy and barriers to therapeutic success. ${ }^{33}$ Non-adherence increases financial burdens on healthcare systems and leads to unnecessary pharmacologic and diagnostic interventions. ${ }^{7-9,16}$ Adherence is the fundamental link between intent and outcome of medical care. ${ }^{16}$

Interventions aimed at improving adherence attempt to maximize successful healthcare delivery. There are various stages of the healthcare process that provide potential for poor adherence. ${ }^{5}$ These include failure to seek early or preventative care, attend follow-up appointments, fill prescriptions, follow physician instructions, ${ }^{34}$ use correct doses or timing, continue treatment for the full duration, or refill prescriptions. ${ }^{8}$ In many instances, non-adherence is unintentional, but patient beliefs may also contribute to intentional deviation from prescribed treatment plans. Ultimately, however, patient decisions regarding treatments are likely to reflect their own beliefs and personal circumstances. In addition to encouraging patient adherence to prescribed medications, healthcare providers should attempt to contribute to the patient's decision-making process. ${ }^{9}$ Three categories of adherence-enhancing strategies have been defined: enabling, consequence, and stimulant. ${ }^{35}$ Enabling strategies arm patients with the tools necessary 
for adherence, and include patient education, simplified medication regimens, cost-effective therapies, and access to medical care and prescriptions. Consequence strategies aim to reinforce adherence by providing incentives for acceptable adherence. Stimulant strategies are aimed at prompting dose-taking. Examples include electronic reminders, environmental cues, peer support, and special packaging or organizers to encourage correct and timely medication usage. Stimulant strategies may have a synergistic effect when combined with enabling strategies to enhance adherence to home medication use. ${ }^{36}$ Methods of measuring adherence varied amongst studies. There is no gold standard measurement of adherence, and this complicates our ability to uniformly quantify adherence. ${ }^{7,37}$ Both direct and indirect measures have been utilized in an attempt to measure medication usage. Direct measures, such as serum or urine drug levels, are more challenging, invasive, expensive, and have limited applications. Their use is restricted to hospitalized patients receiving single-dose, intermittent therapies. ${ }^{34}$ These methods may likewise discount individual pharmacokinetic and metabolic variations.

Indirect measures, which are utilized in the majority of patient adherence studies, include patient medication diaries, interviews, pill counts, prescription filling dates, electronic monitoring devices, and therapeutic or preventative outcome measures. ${ }^{34}$ Electronic monitoring devices, such as MEMS (medication event monitoring system), enable measurement of both frequency and timing of medication dosing. They have also revealed the phenomenon of "white coat adherence," where medication usage significantly increases immediately prior to doctor appointments. ${ }^{38,39}$ MEMS themselves have been postulated to stimulate adherence because they provide evidence of true medication usage, and could be considered a less obtrusive reminder device than phone calls or text messages. ${ }^{39}$

The extent of the relationship between treatment adherence and treatment outcomes has yet to be fully elucidated. Understanding the connection between adherence and certain moderating factors, such as patient beliefs, disease features, or therapeutic regimens, is essential to identifying determinants of treatment outcomes and designing methods to improve patient adherence. Interventions have included the use of reminder mechanisms to maximize medication adherence. In this study we examined the effect of reminders on patient medication adherence using meta-analysis to integrate research findings with statistical analysis of multiple studies. Reminders are one extensively-studied adherence-enhancing strategy. Such reports have provided conflicting evidence for the efficacy of reminder systems in improving adherence to medication usage. The success of reminders is likely to be heavily dependent on other complex determinants of medication usage, such as medication type, patient population, or disease process. We attempt to quantify the correlation between reminder interventions and quantity of adherence, or number of doses taken over a period of time, in order to better assess the overall significance of this intervention

The reminder systems in this review target "treatment" or "secondary" non-adherence, which is the failure to correctly utilize prescribed treatment plans. ${ }^{8,34}$ Patient non-adherence may be intentional, in which the patient purposefully declines to take a medication for reasons that appear rational when subject to analyses; such reasons may include incorrect diagnosis or prescription, development of side effects or adverse reactions, or awareness of a change in one's disease process. ${ }^{40}$ Reminder systems largely target unintentional non-adherence but may also diminish intentional non-adherence by providing patients with feedback while appealing to a desire to appear adherent when use is scrutinized by an outside party. The use of patient reminders has been extensively studied as one method of improving adherence to behavioral, lifestyle, and pharmacologic treatment regimens. Reminders provide recurrent cues, encouragement, or motivation for patients to adhere to medical recommendations, but it is unclear whether their function differs in daily medication usage versus lifestyle modifications or preventative healthcare. Our analysis specifically assesses the use of reminders in influencing adherence to daily medication use.

\section{Methods}

A Medline search was conducted for journal articles published from 1968 through to June 2011. The search was limited to English-language randomized controlled trials which contained the keywords "adherence" or "compliance" and "reminder". This yielded 243 results. Studies of healthcare provider adherence, case reports, and studies analyzing patient adherence to office visits, refills, vaccinations, screening tests, lab work, or exercise, or behavioral modifications were excluded. Included were studies which examined adherence to prescribed medications or substances that have to be utilized at least once daily. This was done so that analysis would more closely reflect medication adherence rather than adherence to lifestyle interventions. We then selected for trials that met the following criteria: utilized a reminderbased intervention, measured adherence as a primary endpoint, and measured quantity of adherence (measured as 
[number of bottle openings or doses taken]/[ doses prescribed during that time $] \times 100$ ) rather than the percentage of the sample meeting a certain definition of adherence. This unit of measurement was selected so that comparison between all control and reminder groups could be performed.

\section{Data analysis}

Medication adherence was measured as the number of doses taken compared to the number prescribed within a set period of time. Some trials reported adherence over the entire study period while some only gave the adherence rate at baseline and endpoint for each group. We averaged these numbers to produce comparable data to trials that reported it over the entire study period. There was no predefined percentage of dose-taking used to define "adherence" versus "non-adherence." Adherence between reminder and control groups was compared using paired $t$-tests. Average adherence between different medication types and monitoring methods was compared using Kruskal-Wallis tests. All statistical analysis was performed using SAS (v9.1; SAS Institute, Cary, NC).

\section{Results}

Eleven trials were analyzed. ${ }^{41-51}$ All studies contained a control group which did not receive any reminder intervention. Sample sizes ranged from 22 to 398. Medications included highly active antiretroviral therapy (HAART), inhaled corticosteroids or long-acting beta-agonists, adapalene gel, Vitamin C, daily sunscreen, prostaglandin eye drops, and angiotensin-converting enzyme (ACE) inhibitors, calcium channel blockers, or beta-blockers (Table 1). Six studies used electronic tracking devices to monitor medication use, four relied upon self-reported compliance, and one used the dose count on an inhaler. Three trials had a phone text message reminder intervention arm, one used regular phone call reminders, one used an interactive voice response phone reminder device, one used video-telephone call reminders, two used pager text reminders, two used programmed electronic audiovisual reminder devices, and one used parental reminders or frequent office visits (Table 1). For those that reported both electronic- and patient-reported adherence rates, we analyzed electronically monitored adherence rates only. Some combined reminder systems with education and development of adherence strategies.

Eight of eleven studies showed a statistically significant increase in adherence for at least one of the reminder group arms compared to the control group. Reminder groups averaged $11.9 \%$ higher adherence than the corresponding control groups (95\% CI for mean: $0.8 \%$ to $22.4 \%$ ). Using a paired $t$-test, reminder groups had higher adherence than the corresponding control groups $(P=0.04)$. Adherence averaged $66.61 \%$ in the groups receiving reminders, compared to $54.71 \%$ in control groups. The range of adherence was $36 \%-88.45 \%$ in the reminder groups and $18.6 \%-86.75 \%$ in the control groups.

No significant difference in adherence rates was seen for patient reported results compared to electronic monitoring systems. Among trials using participant-reported results or pill counts to calculate adherence rates, overall adherence was $62.15 \%$, compared to $60.86 \%$ among trials using electronic monitoring devices $(P=0.72)$. The average reminder group adherence rate was $68.04 \%$ among trials using self-reported adherence and $63.67 \%$ for those relying upon electronic monitoring $(P=1.0)$. In control groups, adherence was $56.25 \%$ for self-reporting or pill count groups versus $53.43 \%$ for electronically monitored groups $(P=0.86)$.

Trials utilizing phone or pager text message reminder interventions had an average adherence rate of $51.31 \%$ in reminder groups. There was no statistically significant difference compared to participants receiving traditional phone calls, video-telephone calls, or interactive voice response system reminders (67.65\% average adherence, $P=0.14)$. The two trials using electronic monitoring systems with integrated audio or audiovisual reminder devices resulted in $84.23 \%$ average adherence, although neither showed a statistically significant increase in adherence over control groups.

The average adherence rate among those receiving HAART therapy was $54.58 \%$ in control groups and $62.58 \%$ in intervention groups, with one of three trials showing a statistically significant improvement in adherence. Adherence rates for those receiving asthma inhaler treatments was $63.13 \%$ among controls and $72.1 \%$ for reminder groups, with both trials showing a significant improvement over controls. For those receiving blood pressure medications, adherence was $77.88 \%$ without intervention and $81.73 \%$ with reminders; one of the two trials showed a statistically significant improvement in adherence $(P=0.03)$. Among those receiving nonprescription medications (daily vitamin $\mathrm{C}$ or sunscreen), adherence among control groups was $24.3 \%$ versus $60.2 \%$ among reminder groups; both demonstrated a statistically significant improvement $(P=0.001,0.001)$. For those receiving prostaglandin eye drops, adherence was $48.5 \%$ and $67.75 \%$ among control and reminder groups, respectively, while for adapalene gel, adherence was 59\% in the control group and $55.33 \%$ for all reminder interventions. 


\section{Discussion}

Dose adherence was significantly increased by reminderbased interventions (65.94\% in the reminder groups versus $54.71 \%$ in the control groups, $P=0.04$ ), showing that it is possible to modify medication adherence rates. It is unclear whether this effect is attributable to the reminders' function as a memory aid or whether the knowledge that their adherence was being monitored prompted participants to utilize medications to a greater extent.

The literature analyzed in this analysis relied upon indirect measures of patient adherence (Table 1). Each of these methods is vulnerable to certain flaws in reliability. Outcome measures may not be directly attributable to medication usage. Self-reporting and pill counts are likely to overestimate adherence, and patient interviews have varying sensitivity among different patient subgroups. ${ }^{52}$ All studies in this analysis used indirect measures of adherence. ${ }^{34}$ There was no significant difference in self-reported and electronically-recorded adherence rates. Of the five trials in this analysis using patient-reported results or dose counts to quantify adherence, three displayed a statistically significant increase in adherence with reminder interventions $(P=0.001$, $P=0.03)$. Despite the opportunity for study participants to provide inflated adherence rates when self-reporting medication usage, adherence rates in self-reporting and pill count intervention groups were comparable to those monitored via electronic tracking devices (68.04\% versus $63.67 \%, P=1.0$ ). Electronically measured medication usage is thought to be a more reliable assessment of adherence; the fact that these rates were comparable to self-reported rates implies that reminders were equally successful in both groups, or that monitoring increased participants' awareness of medication usage and exerted a direct positive effect on adherence rates. Five of the six trials utilizing MEMS caps or other electronic monitoring devices showed a statistically significant increase in adherence in at least one intervention arm. This suggests that monitoring devices themselves may act to increase adherence independently of other interventions, or may act as a reminder by increasing awareness of medication usage monitoring.

It is unclear whether one type of reminder system has a more significant impact on adherence. When comparing text and voice-based interventions, those receiving phone or pager texts had an absolute average adherence rate of $51.31 \%{ }^{28,30,31,34,35}$ compared to $67.65 \%$ among those receiving traditional phone calls, video-telephone calls, or calls from automated interactive voice response systems. ${ }^{33,36,38}$ Four out of five text message interventions demonstrated a statistically significant improvement in adherence, as did four of the five voice-based interventions. The two electronic monitoring devices that had integrated reminder alarms ${ }^{29,37}$ both had high absolute rates of adherence $(88.45 \%$ and $80 \%)$, yet failed to generate a statistically significant improvement over controls.

Another aspect of reminder systems that may influence adherence rates is the message behind the reminder, or put another way, what is being communicated to the patient. The more a person is intrinsically motivated towards a certain task the more likely it is the person will engage and persist in the task. ${ }^{53,54}$ Physicians may increase positive health outcomes, including adherence, if they interact in an "autonomy supportive" rather than "controlling" manner when treating patients and their families ${ }^{55}$ It could be that reminder systems that target a patient's self-reported reasons for adherence are more effective than neutral statements or warnings that seem more externalized for the patient.

The type of medication may also influence observed adherence rates, yet it is difficult to discern a pattern from our limited analysis. Chronic and asymptomatic illnesses may be most resistant to adherence-enhancing strategies. ${ }^{1}$ Yet in this analysis, those receiving blood pressure medications had the highest average rates of adherence in both control and reminder groups $(77.88 \%$ and $81.73 \%$ ) followed by those receiving asthma therapy (63.13\% versus $72.1 \%)$. Among three trials in which participants received HAART therapy, only one of three showed a statistically significant improvement in adherence with reminders, and average adherence among non-reminder groups was only $54.58 \%$, compared to $62.58 \%$ among those receiving the reminder intervention.

Cost-effectiveness and long-term practicality of the reminder systems used in these studies are likely to inhibit their widespread implementation. Repeated phone calls, text messages, beeper systems, or frequent follow-up appointments for relatively stable conditions require significant financial investment and manpower. Repeated reminders may be viewed as intrusive rather than helpful. More practical reminder-based interventions include blister-packs to measure dose usage, calendars, dose counters, and other special containers that enhance awareness of dose-usage. Evidence also suggests that combination interventions confer greater efficacy than single-method approaches. Combining adherence-modifying strategies like reminders with other interventions produces a greater overall effect than any intervention alone. ${ }^{56-58}$ Further interventions may entail adapting treatment plans to patient preferences, simplifying treatment regimens, enlisting family support, providing education regarding side effects and 
Table I Randomized controlled trials measuring percent adherence in reminder and control groups

\begin{tabular}{|c|c|c|c|c|c|}
\hline Study & Control & $\begin{array}{l}n \\
\text { (total) }\end{array}$ & $\begin{array}{l}\text { Adherence } \\
\text { (control group; \%) }\end{array}$ & Reminder & Reminder description \\
\hline Armstrong ${ }^{48}$ & No reminder & 35 & 30.00 & $\begin{array}{l}\text { Phone text } \\
\text { reminder }\end{array}$ & $\begin{array}{l}\text { A daily text message containing the day's weather } \\
\text { and a reminder to apply sunscreen ("Tues. Sunny. } \\
\text { High 7I, Low 6I. Slap on some sunscreen today.") }\end{array}$ \\
\hline Standbygaard ${ }^{44}$ & No reminder & 12 & 77.15 & $\begin{array}{l}\text { Phone text } \\
\text { reminder }\end{array}$ & $\begin{array}{l}\text { Daily short message service (SMS) text reminder at } \\
10 \text { am for } 8 \text { weeks telling participants to take their } \\
\text { asthma medication }\end{array}$ \\
\hline Okeke $^{49}$ & No reminder & 31 & 48.50 & $\begin{array}{l}\text { Phone call } \\
\text { reminder }\end{array}$ & $\begin{array}{l}\text { Reminder telephone calls from the coordinator } \\
\text { once per week for one month then every other } \\
\text { week, which included administration of a questionnaire } \\
\text { about drop-taking behavior, difficulty with drops side } \\
\text { effects, and opportunities for participant questions }\end{array}$ \\
\hline Christensen ${ }^{50}$ & No reminder & 179 & 86.75 & $\begin{array}{l}\text { Programmed } \\
\text { electronic } \\
\text { audiovisual } \\
\text { reminder }\end{array}$ & $\begin{array}{l}\text { The device is operated with tablet blister cards and } \\
\text { was customized to fit the blister cards of the study } \\
\text { medication. The device gives the patient an audiovisual } \\
\text { reminder when it is time to take the medication }\end{array}$ \\
\hline Cococila $^{47}$ & No reminder & 48 & 18.60 & $\begin{array}{l}\text { Phone text } \\
\text { reminder }\end{array}$ & $\begin{array}{l}3 \text { types of daily message were sent. Basic message } \\
\text { ending in a question mark (“Hi, its Tim: any Vitamin C } \\
2 \text { day?"); reinforcing message to those who replied } \\
\text { as expected including encouraging statements with } \\
\text { brief jokes and ending with a smiley (“Tim here again: } \\
\text { Ur doing super! Tip: } 2 \text { steal ideas from one person is } \\
\text { plagiarism; } 2 \text { steal from many is research!:)"); } \\
\text { and correcting message to those who did not } \\
\text { acknowledge the basic reminders (with non-amusing } \\
\text { feedback with the importance of taking the vitamin } \\
\text { (“Again Tim: do your best to take the vitamins: they } \\
\text { help fight cold and flu!") }\end{array}$ \\
\hline \multirow[t]{2}{*}{ Fulmer ${ }^{51}$} & No reminder & 18 & 69.00 & $\begin{array}{l}\text { Phone call } \\
\text { reminder }\end{array}$ & \\
\hline & & & & $\begin{array}{l}\text { Videotelephone } \\
\text { call reminder }\end{array}$ & $\begin{array}{l}\text { A daily videotelephone telephone call lasting } \\
3-5 \text { minutes consisting of a brief greeting and a } \\
\text { question asking whether participants had traken } \\
\text { their medications the previous day }\end{array}$ \\
\hline Safren ${ }^{41}$ & $\begin{array}{l}\text { Medications } \\
\text { monitoring } \\
\text { only }\end{array}$ & 19 & 55.00 & $\begin{array}{l}\text { Pager text } \\
\text { reminder }\end{array}$ & $\begin{array}{l}\text { Daily text message included dose reminders } \\
\text { including drug name, number of pills, and } \\
\text { specific decriptions (eg: "take } 2 \text { Combivir with } \\
\text { water" or "take the } 2 \text { blue pills now") }\end{array}$ \\
\hline Bender ${ }^{45}$ & No reminder & 25 & 49.10 & $\begin{array}{l}\text { Interactive voice } \\
\text { response } \\
\text { system reminder }\end{array}$ & $\begin{array}{l}2 \text { programmed calls separated by one month including } \\
\text { an explanation of how the call worked, followed by } \\
3 \text { questions asking whether the participant had } \\
\text { experienced asthma symptoms in the past week: if } \\
\text { their anwer was affirmative participants were told } \\
\text { that controller medications should help prevent these } \\
\text { symptoms; they were also asked wether they were } \\
\text { filling and using their medications }\end{array}$ \\
\hline Andrade ${ }^{42}$ & $\begin{array}{l}\text { Monthly } \\
\text { adherence } \\
\text { counseling, } \\
\text { no reminders }\end{array}$ & 29 & 65.00 & $\begin{array}{l}\text { Programmed } \\
\text { electronic } \\
\text { voice reminder } \\
\text { device }\end{array}$ & $\begin{array}{l}\text { Disease Management Assistance System (DMAS), a } \\
\text { battery powered electronic device that produces a } \\
\text { timed, programmed voice message prompting subjects } \\
\text { to take their antiretrovitrals }\end{array}$ \\
\hline Simoni ${ }^{43}$ & $\begin{array}{l}\text { No } \\
\text { intervention }\end{array}$ & 57 & 43.75 & $\begin{array}{l}\text { Pager text } \\
\text { reminder }\end{array}$ & $\begin{array}{l}\text { A minimum of } 3 \text { daily text messages included dose } \\
\text { reminders, educational messages about the disease and } \\
\text { treatment, entertainment and adherence assesments }\end{array}$ \\
\hline Yentzer $^{46}$ & No reminder & 12 & 59.00 & $\begin{array}{l}\text { Phone call reminder } \\
\text { Parental reminder } \\
\text { Frequent office visits }\end{array}$ & \\
\hline Average adherence & & & 54.71 & & \\
\hline Standard deviation & & & 19.91 & & \\
\hline
\end{tabular}




\begin{tabular}{lllll}
\hline $\begin{array}{l}\mathbf{n} \\
\text { (total) }\end{array}$ & $\begin{array}{l}\text { Adherence } \\
\text { (test group; } \%)\end{array}$ & P-value & monitoring \\
\hline 35 & 56.10 & Sunscreen & 0.001 & Electronic monitoring device \\
10 & 79.70 & $\begin{array}{l}\text { Discos Seretide (Inhaled corticosteroid } \\
\text { and long-acting beta-agonist) }\end{array}$ & 0.019 & Dose count on inhaler disc \\
35 & 67.75 & Prostaglandin eye drops & 0.01 & Dosing Aid recording device
\end{tabular}

219

51

64.30

75.00

83.00

17

25

25

64.50

29

80.00

44.75

$\begin{array}{ll}8 & 48.00 \\ 14 & 36.00\end{array}$

$12 \quad 82.00$

66.61

15.93
Ace-inhibitors, calcium channel-blockers (CCB), beta-blockers

HAART

Fluticasone/sal merterol (inhaler)

Highly active antiretroviral therapy

(HAART)

HAART

adapalene
$<0.05$

$<0.05$

0.03

0.0032

0.25

$>0.5$

$>0.5$

$>0.5$

$<0.5$
Self reported compliance

Self reported compliance
Medication event monitoring system (MEMS) caps

Self reported compliance

Electronic tracking device 
expected outcomes, monitoring adherence, and providing patient feedback. When attempting to improve adherence, interventions should aim to improve patient understanding, recall, and motivation. ${ }^{59}$ Reminders potentially target each of these factors and supplement additional patient education strategies. They may be best utilized in populations for whom forgetfulness is a major cause of unintentional nonadherence.

The studies used in this analysis have several limitations. The data are limited by imperfect measures of adherence due to variability in data collection methods. In many of these trials, patients were aware that they were being monitored and this could be expected to influence adherence. Studies may be limited by their inability to determine whether reminder intervention improved dose-taking behavior or simply increased use of medication monitors or disposal of pills. This analysis does not correlate adherence rates with treatment and disease outcomes, so the overall effect of the observed changes in adherence cannot be determined. The necessary duration of reminder systems for optimal improvement in adherence was not determined but likely contributed to variations seen in reminder efficacy. It is likely that concomitant educational efforts in the study populations, such as instructions regarding proper administration and importance of correct dosing schedules, contributed to improved patient adherence, both in reminder and control arms. Approaches used in these studies were simple compared to most chronic disease regimens. Further research is needed to identify those reminder mechanisms which have the greatest effect on maximizing adherence and to study multifaceted versus single-intervention approaches. The search strategy could have missed relevant studies which were categorized by disease rather than adherence. Studies yielding significant results are more likely to have reached publication, and studies may only be conducted on conditions in which problematic adherence rates were expected.

It appears that patient medication use may be improved by reminder-based interventions. Strategies directed at improving medication-taking behavior should target the underlying barriers to adherence. Reminders may therefore provide a useful adjunct to adherence-enhancing strategies, particularly in populations for whom recurrent cues are helpful in assuring correct medication usage.

\section{Acknowledgment}

The Center for Dermatology Research is supported by an unrestricted educational grant from Galderma Laboratories, LP.

\section{Disclosures}

Dr Feldman has received research, speaking and/or consulting support from GSK/Stiefel, National Biological Corporation, Galderma Laboratories, Abbott, Amgen, Astellas, and Centocor. Dr Feldman owns stock in the patient satisfaction website, http://www.DrScore.com. The other authors have no conflicts to disclose.

\section{References}

1. DiMatteo MR. Enhancing patient adherence to medical recommendations. JAMA. 1994;271(1):79-83.

2. Korsch BM, Gozzi EK, Francis V. Gaps in doctor-patient communication. 1: Doctor-patient interaction and patient satisfaction. Pediatrics. 1968;42(5):855-871.

3. Davis MS. Variations in patients' compliance with doctors' advice: An empirical analysis of patterns of communication. Am J Public Health Nations Health. 1968;58(2):274-288.

4. Epstein LH, Cluss PA. A behavioral medicine perspective on adherence to long-term medical regimens. J Consult Clin Psychol. 1982;50(6):950-971.

5. Vermeire E, Hearnshaw H, Van Royen P, Denekens J. Patient adherence to treatment: three decades of research. A comprehensive review. J Clin Pharm Ther. 2001;26(5):331-342.

6. Horne R. Representation of medication and treatment: advances in theory and measurements. In: Petrie R, Weinlan J, editors. Perceptions of Health and Illness: Current Research and Applications. London: Harwood Academic; 1979:155-188.

7. Morris LS, Schulz RM. Patient compliance - an overview. J Clin Pharm Ther. 1992;17(5):283-295.

8. Donovan JL, Blake DR. Patient non-compliance: deviance or reasoned decision-making? Soc Sci Med. 1992;34(5):507-513.

9. Donovan JL. Patient decision making. The missing ingredient in compliance research. Int J Technol Assess Health Care. 1995; 11(3):443-455.

10. Hays RD, Kravitz RL, Mazel RM, et al. The impact of patient adherence on health outcomes for patients with chronic disease in the Medical Outcomes Study. J Behav Med. 1994;17(4):347-360.

11. Sackett DL, Snow JC. The magnitude of compliance and noncompliance. In: Haynes RB, Taylor DW, Sackett DL, editors. Compliance in Health Care. Baltimore: The John Hopkins University Press; 1979:11-22.

12. Lassen LC. Patient compliance in general practice. Scand J Prim Health Care. 1989;7(3):179-180.

13. Griffith S. A review of the factors associated with patient compliance and the taking of prescribed medicines. Br J Gen Pract. 1990; 40(332):114-116.

14. Dunbar J. Adherence to medical advice: A review. Int J Mental Health. 1980;9:70-87.

15. Lieberman JA 3rd. Compliance issues in primary care. J Clin Psychiatry. 1996;57 (Suppl 7):76-82; discussion 83-85.

16. Urquhart J. Patient non-compliance with drug regimens: measurement, clinical correlates, economic impact. Eur Heart J. 1996;17 (Suppl A): 8-15.

17. Roberson MH. The meaning of compliance: patient perspectives. Qual Health Res. 1992;2(1):7-26.

18. Sackett DL. Introduction. In: Haynes B, Taylor DW, Sackett DL, editors. Compliance in Health Care. Baltimore: The Johns Hopkins Press; 1979:1-7.

19. Dracup KA, Meleis AI. Compliance: an interactionist approach. Nurs Res. 1982;31(1):31-36.

20. Sackett DL, Haynes RB, Gibson ES, et al. Randomised clinical trial of strategies for improving medication compliance in primary hypertension. Lancet. 1975;1(7918):1205-1207. 
21. DiMatteo MR, Hays RD, Gritz ER, et al. Patient adherence to cancer control regimens: Scale development and initial validation. Psychol Assessment. 1993;5:102-112.

22. DiMatteo MR, Lepper HS, Croghan TW. Depression is a risk factor for noncompliance with medical treatment: meta-analysis of the effects of anxiety and depression on patient adherence. Arch Intern Med. 2000;160(14):2101-2107.

23. Bosworth HB, editor. Improving Patient Treatment Adherence: A Clinician Guidebook. New York: Springer; 2010.

24. Lehane E, McCarthy G. Medication non-adherence - exploring the conceptual mire. Int J Nurs Pract. 2009;15(1):25-31.

25. Ngoh LN. Health literacy: a barrier to pharmacist-patient communication and medication adherence. J Am Pharm Assoc (2003). 2009; 49(5):e132-e146.

26. Christensen A, Osterberg LG, Hansen EH. Electronic monitoring of patient adherence to oral antihypertensive medical treatment: a systematic review. J Hypertens. 2009;27(8):1540-1551.

27. De Bleser L, Matteson M, Dobbels F, Russell C, De Geest S. Interventions to improve medication-adherence after transplantation: a systematic review. Transpl Int. 2009;22(8):780-797.

28. Julius RJ, Novitsky MA Jr, Dubin WR. Medication adherence: a review of the literature and implications for clinical practice. J Psychiatr Pract. 2009;15(1):34-44

29. Haynes RB, Montague P, Oliver T, McKibbon KA, Brouwers MC, Kanani R. Interventions for helping patients to follow prescriptions for medications. Cochrane Database Syst Rev. 2000;2:CD000011.

30. Steiner A, Vetter W. Patient compliance/noncompliance, determining factors, physician-patient interaction. Schweiz Rundsch Med Prax. 1994;83(33):889-894.

31. Marinker M. From compliance to concordance: achieving shared goals in medicine taking. BMJ. 1997:314:747-748.

32. Haynes B, Taylor DW, Sackett DL. Compliance in Health Care. Baltimore: The John Hopkins University Press; 1979.

33. Melnikow J, Kiefe C. Patient compliance and medical research: issues in methodology. J Gen Intern Med. 1994;9(2):96-105.

34. Gordis L. Conceptual and methodologic problems in measuring patient compliance. In: Haynes B, Taylor DW, Sackett DL, editors. Compliance in Health Care. Baltimore: The Johns Hopkins University Press; 1979:23-45.

35. McKenney JM, Munroe WP, Wright JT Jr. Impact of an electronic medication compliance aid on long-term blood pressure control. J Clin Pharmacol. 1992;32(3):277-283.

36. Cargill JM. Medication compliance in elderly people: influencing variables and interventions. J Adv Nurs. 1992;17(4):422-426.

37. Kruse W. Patient compliance with drug treatment - new perspectives on an old problem. Clin Investig. 1992;70(2):163-166.

38. Vander Stichele R. Measurement of patient compliance and the interpretation of randomized clinical trials. Eur J Clin Pharmacol. 1991;41(1):27-35.

39. Raynor DK. Patient compliance: the pharmacist's role. Int J Pharm Pract. 1992;1(3):126-135.

40. Britten N. Patients' ideas about medicines: a qualitative study in a general practice population. Br J Gen Pract. 1994;44(387):465-468.

41. Safren SA, Hendriksen ES, Desousa N, Boswell SL, Mayer KH. Use of an on-line pager system to increase adherence to antiretroviral medications. AIDS Care. 2003;15(6):787-793.
42. Andrade AS, McGruder HF, Wu AW, et al. A programmable prompting device improves adherence to highly active antiretroviral therapy in HIV-infected subjects with memory impairment. Infect Dis. 2005;41(6):875-882.

43. Simoni JM, Huh D, Frick PA, et al. Peer support and pager messaging to promote antiretroviral modifying therapy in Seattle: a randomized controlled trial. J Acquir Immune Defic Syndr. 2009;52(4): 465-473.

44. Strandbygaard U, Thomsen SF, Backer V. A daily SMS reminder increases adherence to asthma treatment: a three-month follow-up study. Respir Med. 2010;104(2):166-171.

45. Bender BG, Apter A, Bogen DK, et al. Test of an interactive voice response intervention to improve adherence to controller medications in adults with asthma. J Am Board Fam Med. 2010;23(2) 159-165.

46. Yentzer BA, Gosnell AL, Clark AR, et al. A randomized controlled pilot study of strategies to increase adherence in teenagers with acne vulgaris. J Am Acad Dermatol. 2011;64(4):793-795.

47. Cococila M, Archer N, Haynes RB, Yuan Y. Can wireless text messaging improve adherence to preventive activities? Results of a randomised controlled trial. Int J Med Inform. 2009;78(4):230-238.

48. Armstrong AW, Watson AJ, Makredes M, et al. Text-message reminders to improve sunscreen use: a randomized, controlled trial using electronic monitoring. Arch Dermatol. 2009;145(11):1230-1236.

49. Okeke CO, Quigley HA, Jampel HD, et al. Interventions improve poor adherence with once daily glaucoma medications in electronically monitored patients. Ophthalmology. 2009;116(12):2286-2293.

50. Christensen A, Christrup LL, Fabricius PE, et al. The impact of an electronic monitoring and reminder device on patient compliance with antihypertensive therapy: a randomized controlled trial. J Hypertens. 2010;28(1):194-200.

51. Fulmer TT, Feldman PH, Kim TS, et al. An intervention study to enhance medication compliance in community-dwelling elderly individuals. J Gerontol Nurs. 1999;25(8):6-14.

52. Stewart M. The validity of an interview to assess a patient's drug taking Am J Prev Med. 1987;3(2):95-100.

53. Williams GC, Frankel RM, Campbell TL, Deci EL. Research on relationship-centered care and healthcare outcomes from the Rochester biopsychosocial program: A self-determination theory integration. Fam Sys Health. 2000;18:79-90.

54. Deci EL, Ryan RM. Intrinsic Motivation and Self-determination in Human Behavior. New York: Plenum Press; 1985.

55. Ryan RM, Deci EL. Self-determination theory and the facilitation of intrinsic motivation, social development, and well-being. Am Psychol. 2000;55(1):68-78.

56. Sanson-Fisher RW, Campbell EM, Redman S, Hennrikus DJ. Patient-provider interactions and patient outcomes. Diabetes Educ. 1989;15(2):134-138.

57. Steiner A, Vetter W. Patient compliance-possibilities for improvement. Praxis (Bern 1994). 1995;84(3):58-62.

58. Roter DL, Hall JA, Merisca R, Nordstrom B, Cretin D, Svarstad B. Effectiveness of interventions to improve patient compliance: a metaanalysis. Med Care. 1998;36(8):1138-1161.

59. King NJ, Peck CL. Enhancing patient compliance with medical regimens: strategies for the general practitioner. Aust Fam Physician. 1981;10(12):954-959.
Patient Preference and Adherence

\section{Publish your work in this journal}

Patient Preference and Adherence is an international, peer-reviewed, open access journal focusing on the growing importance of patient preference and adherence throughout the therapeutic continuum. Patient satisfaction, acceptability, quality of life, compliance, persistence and their role in developing new therapeutic modalities and compounds to

\section{Dovepress}

optimize clinical outcomes for existing disease states are major areas of interest. This journal has been accepted for indexing on PubMed Central. The manuscript management system is completely online and includes a very quick and fair peer-review system. Visit http://www.dovepress.com/ testimonials.php to read real quotes from published authors. 